\title{
Isomerization of Linear to Angular [3]Phenylene and PAHs Under Flash Vacuum Pyrolysis Conditions
}

\author{
Peter I. Dosa, Andreas Schleifenbaum, and K. Peter C. Vollhardt* \\ Center for New Directions in Organic Synthesis, Department of Chemistry, University \\ of California at Berkeley, and the Chemical Sciences Division, Lawrence Berkeley \\ National Laboratory, Berkeley, California 94720-1460 \\ vollhard@cchem.berkeley.edu
}

Received Date (will be automatically inserted after manuscript is accepted)

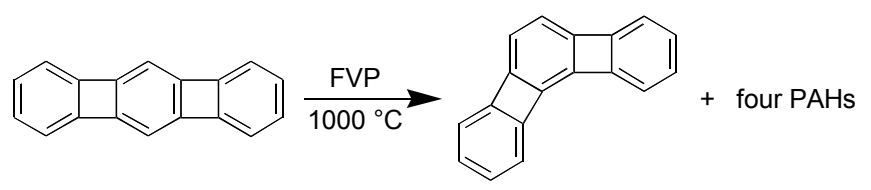

Flash vacuum pyrolysis (FVP) of linear [3]phenylene affords its angular counterpart and the same mixture of polycyclic aromatic hydrocarbon isomers as that observed on FVP of angular [3]phenylene. A mechanism, supported by $a^{13} \mathrm{C}$ labeling study, is proposed to explain these results.

The phenylenes are high-energy potential precursors to polycyclic aromatic hydrocarbons (PAHs) including fullerene substructures. ${ }^{1}$ Their thermal chemistry is also of interest because of the possible isomerization of one phenylene to another, which holds the synthetic potential to access hitherto unknown isomers. Such an isomerization was recently demonstrated by Scott. $^{2} \mathrm{We}$ present here the FVP of linear [3]phenylene $(\mathbf{1}){ }^{3}$ the reinvestigation of the FVP of angular [3]phenylene (2), and

(1) (a) Matzger, A. J.; Vollhardt, K. P. C. Chem. Commun. 1997, 1415. (b) Wiersum, U. E.; Jenneskens, L. W. Tetrahedron Lett. 1993, 34, 6615. (c) Brown, R. F. C.; Choi, N.; Coulston, K. J.; Eastwood, F. W.; Wiersum, U. E.; Jenneskens, L. W. Tetrahedron Lett. 1994, 35, 4405.

(2) (a) Preda, D. V.; Scott, L. T. Org. Lett. 2000, 2, 1489. (b) see also: Sarobe, M.; Kwint, H. C.; Fleer, T.; Havenith, R. W. A.; Jenneskens, L. W.; Vlietstra, E. J.; van Lenthe, J. H.; Wesseling, J. Eur. J. Org. Chem. 1999, 1191.

(3) Berris, B. C.; Hovakeemian, G. H.; Lai, Y.; Mestdagh, H.; Vollhardt, K. P. C. J. Am. Chem. Soc. 1985, 107, 5670. a ${ }^{13} \mathrm{C}$ study leading to a new mechanistic proposal for the isomerization of $\mathbf{1}$ and $\mathbf{2}$ into PAHs.

In a previous study, it was found that the FVP of $\mathbf{2}$ at $1000{ }^{\circ} \mathrm{C}$ and $2 \times 10^{-2}$ torr led to the formation of benzo[ghi]fluoranthene (3) in $10 \%$ yield. ${ }^{\text {a }}$ Repeating this experiment using a turbomolecular vacuum pump $\left(5 \times 10^{-7}\right.$ torr) significantly improved this yield to $24 \%$ and facilitated the isolation and structural elucidation ${ }^{4}$ of three additional PAHs that were previously unidentified:

(4) The products were separated by HPLC and their identities confirmed by comparison of their NMR and UV spectra with those published in the literature. For spectra of $\mathbf{3}$ and 6, see: Sarobe, M.; Jenneskens, L. W. J. Org. Chem. 1997, 62, 8247 and Karcher, W.; Fordham, R. J.; Dubois, J. J.; Glaude, P. G. J. M.; Ligthart, J. A. M. Spectral Atlas of Polycyclic Aromatic Compounds, Reidel, Dordrecht, 1985. For spectra of 4, see: Sarobe, M.; Snoeijer, J. D.; Jenneskens, L. W.; Slagt, M. Q.; Zwikker, J. W. Tetrahedron Lett. 1995, 36, 8489. For spectra of 5, see: Mulder, P. P. J.; Boere, B. B.; Cornelisse, J.; Lugtenburg, J. Recl. Trav. Chim. Pay-Bas 1993, 112, 255. 
acefluoranthylene $\quad(\mathbf{4}, \quad 11 \%), \quad$ cyclopent $[h i]$ acephenanthrylene $(\mathbf{5}, 3 \%)$, and the highly mutagenic ${ }^{5}$ cyclopenta[cd]pyrene $(6,7 \%)$. Traces of other PAHs, including fluoranthene and benz $[a]$ anthracene, were also present. ${ }^{\text {la }}$ A small amount of $2(4 \%)$ was recovered under these conditions.

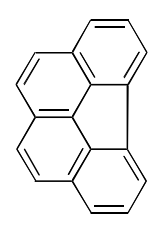

3
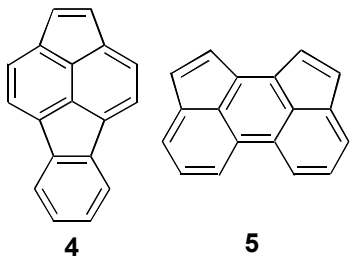

5

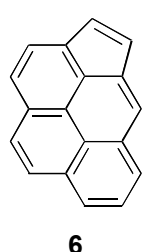

The corresponding FVP of linear [3]phenylene (1) produced a strikingly similar product mixture: $\mathbf{3}(10 \%), \mathbf{4}$ $(4 \%), 5(1 \%)$, and $\mathbf{6}(2 \%)$, in addition to recovered $\mathbf{1}(17 \%)$ and, most significantly, its isomer $\mathbf{2}(1 \%)$. These results strongly imply the intermediacy of (the presumed to be more stable) ${ }^{6} \mathbf{2}$ in the FVP of $\mathbf{1}$. A likely mechanism for this initial isomerization, paralleling that proposed by Scott for the conversion of benzo[b]biphenylene to benzo $[a]$ biphenylene, ${ }^{2}$ is presented in Scheme 1.

\section{Scheme 1}
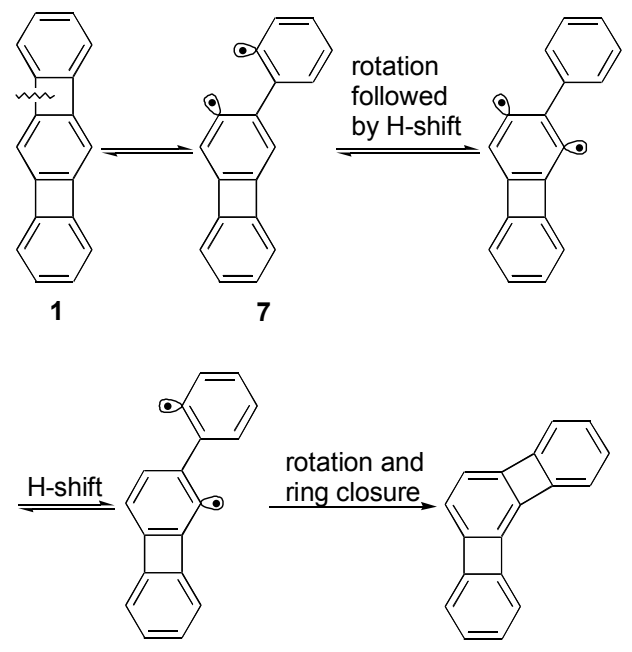

2

The isolation of 4-6, in addition to $\mathbf{3}$, is intriguing and suggested that the thermal conversion of $\mathbf{2}$ (and 1) was more complicated than previously envisaged, ${ }^{\text {la }}$ warranting further investigation. A series of control experiments demonstrated that 3-6 did not interconvert under the reaction conditions. ${ }^{7}$ To gain insight into the pathways that lead to 3-6, a labeling study was performed using ${ }^{13} \mathrm{C}_{2^{-}}$ angular [3]phenylene (2a) prepared as shown in Scheme 2.

(5) Jacob, J. Pure Appl. Chem. 1996, 68, 301.

(6) Schulman, J. M.; Disch, R. L. J. Am. Chem. Soc. 1996, 118, 8470.

(7) $\mathbf{3}$ and $\mathbf{6}$ are known to interconvert at temperatures greater than those used in the present study, see: Plater, M. J. Tetrahedron Lett. 1994, 35, 6147 and Jenneskens, L. W.; Sarobe, M.; Zwikker, J. W. Pure Appl. Chem. 1996, 68, 219.
Thus, acetylene- ${ }^{13} \mathrm{C}_{2}$ was coupled to 1-iodo-2(trimethylsilylethynyl)benzene using a general procedure, ${ }^{8}$ modified to optimize the yields based on labeled starting material. The resulting $\mathbf{8}$ was deprotected and cyclized in a stepwise protocol $^{9}$ to furnish $\mathbf{2 a}$.

\section{Scheme 2}
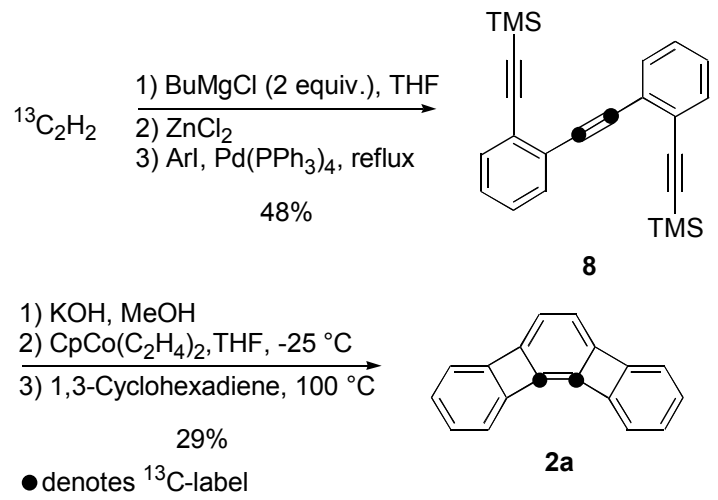

$2 a$

Pyrolysis of 2a produced labeled 3-6, in addition to unchanged $2 \mathbf{a}^{4}{ }^{4}$ The absence of scrambling in the starting material ruled out equilibration of $\mathbf{2}$ with 1 prior to rearrangement. The major label locations in 3-6 (shown in Figure 1$)^{10}$ were determined by ${ }^{13} \mathrm{C}$ NMR analysis, which required the assignment of the ${ }^{13} \mathrm{C}$ NMR spectra of these compounds by HMQC, HMBC, and other NMR techniques (see Supporting Information). The vicinal nature of the label pairs in the products was evident from the observed strong carbon-carbon couplings, with $J$ values between 50 and $69 \mathrm{~Hz}$ (except in the symmetrical case 5a).

These observations require a revision of the original mechanism proposed for the conversion of $\mathbf{2}$ to $3{ }^{1 \text { a }}$ as it predicts the generation of only one isotopomer (3b) and cannot be readily adapted to explain the formation of 4-6. While the literature provides several options, ${ }^{11}$ any reasonable mechanistic description must account for the nature of the observed isotopomers of the products and the ratios in which they are formed. The suggestions presented in Schemes 3 and 4 (leading to 3, 4, and 6) and in Scheme 5 (leading to 5) do so and rely on precedented steps. These steps include the homolytic bond cleavage of strained rings followed by radical hydrogen shifts and radical recombination, ${ }^{2}$ hydrogen shift/ring contractions, ${ }^{11 a}$ and carbene formation/insertion reactions. ${ }^{1 \mathrm{~b}, 1 \mathrm{c}, 1 \mathrm{lb}}$

(8) Negishi, E.; Kotora, M.; Xu, C. J. Org. Chem. 1997, 62, 8957.

(9) Diercks, R.; Eaton, B. E.; Gürtzgen, S; Jalisatgi, S.; Matzger, A. J.; Radde, R. H.; Vollhardt, K. P. C. J. Am. Chem. Soc. 1998, 120, 8247.

(10) There was spectral evidence for additional minor label scrambling in all products which was not amenable to analysis. However, the finality of the label distribution could be ascertained at least for $3-{ }^{13} \mathrm{C}_{2}$, for which sufficient quantities were available to allow for repyrolysis under the same conditions. This control experiment showed no discernible change in the ${ }^{13} \mathrm{C}$ NMR spectrum.

(11) For recent mechanistic reviews, see: (a) Necula, A.; Scott, L. T. J. Anal. Appl. Pyrol. 2000, 54, 65 and (b) Brown, R. F. C. Eur. J. Org. Chem. 1999, 3211. 


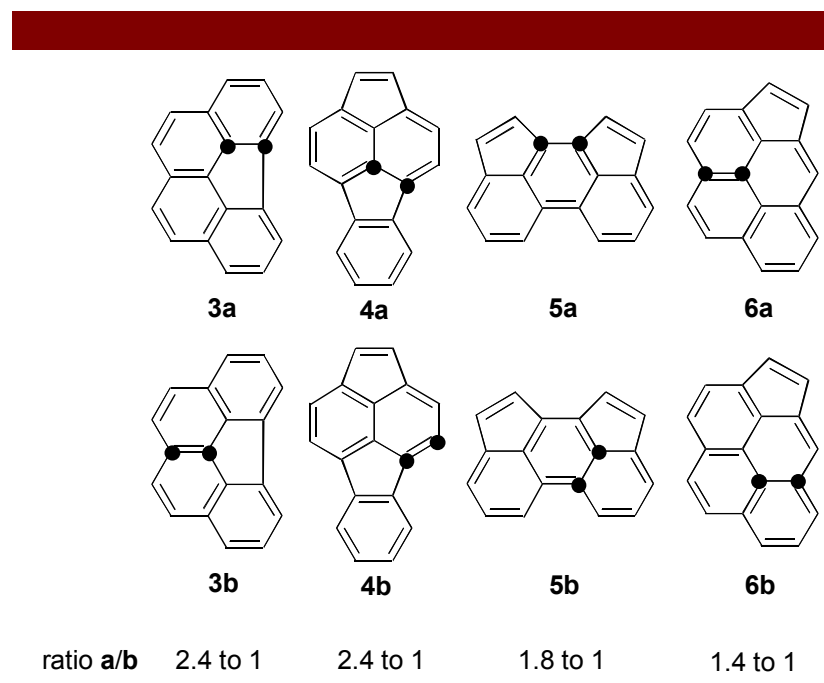

Figure 1. The major isotopomers isolated from the FVP of $\mathbf{2 a}$ and their relative abundances, based on normalized ${ }^{13} \mathrm{C}$ NMR signal intensities.

The cornerstone of Schemes 3 and 4 is an initial StoneWales rearrangement of $\mathbf{2 a}$, as originally proposed. ${ }^{\text {1a }}$ While such a reorganization has never been observed and is calculated to be (normally) energetically too demanding, ${ }^{12}$ the high strain $(99.7 \mathrm{kcal} / \mathrm{mol})$ in $\mathbf{2}^{13}$ may make this step feasible. Alternatively, a stepwise sequence may be followed. In either case, dibenzoacepentalene $(\mathbf{9})^{14}$ would be the first intermediate. From 9, two different pathways can be followed. Thus, homolytic bond cleavage (Scheme 3), followed by hydrogen shifts and bond formation, would result in $\mathbf{3 a}, \mathbf{4 b}$, and $\mathbf{6 b}$ by a sequence of carbene formation/insertion reactions and hydrogen shift/ring contractions. The preponderance of $\mathbf{3 a}$ in the total mixture of products would then be precipitated by its early appearance in the scheme and the energetically favorable nature of step $b$.

\section{Scheme 4}

(12) See: Slanina, Z.; Zhao, X.; Uhlík, F.; Ozawa, M.; Ōsawa, E. J. Organomet. Chem. 2000, 599, 57, and references therein.

(13) Beckhaus, H.-D.; Faust, R.; Matzger, A. J.; Mohler, D. L.; Rogers, D. W.; Rüchardt, C.; Sawhney, A. K.; Verevkin, S. P.; Vollhardt, K. P. C.; Wolff, S. J. Am. Chem. Soc. 2000, 122, 7819.

(14) The synthesis of acepentalene and its tribenzo derivative have been reported: Haag, R.; Schröder, D.; Zywietz, T.; Jiao, H.; Schwarz, H.; Schleyer, P. v. R.; de Meijere, A.; Angew. Chem., Int. Ed. Engl. 1996, 35, 1317; Haag, R.; Ohlhorst, B.; Noltemeyer, M.; Fleischer, R.; Stalke, D.; Schuster, A.; Kuck, D.; de Meijere, A. J. Am. Chem. Soc. 1995, 117 , 10474.

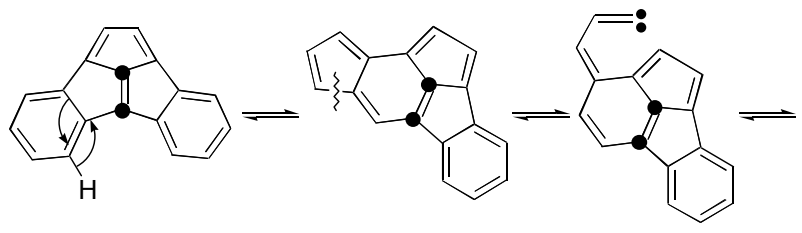

9 (209)

(193)

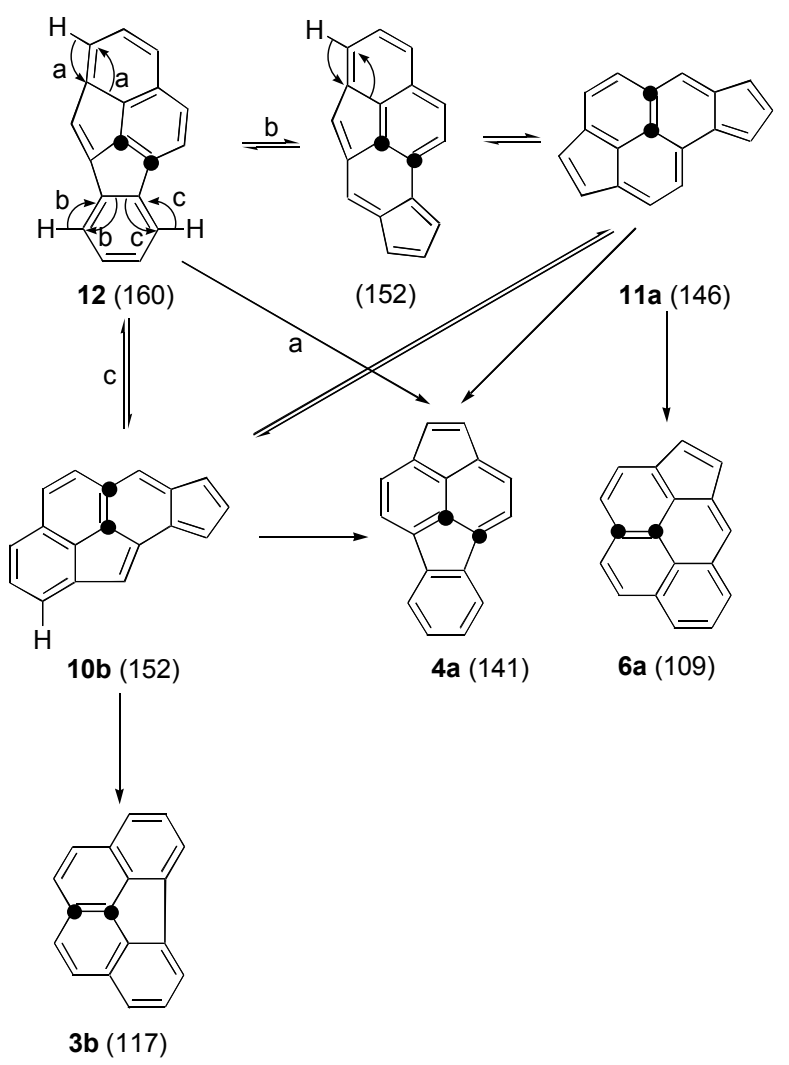

${ }^{\text {a }}$ Numbers in parentheses are AM1 $\Delta H_{\mathrm{f}}{ }^{\circ}$ values in $\mathrm{kcal} / \mathrm{mol}$.

Scheme 4 depicts an alternative (perhaps minor) reorganization of $\mathbf{9}$, initiated by a hydrogen shift/ring contraction at the benzene nucleus, followed by a combination of carbene formation/insertion and further hydrogen shift/ring contractions to end up in $\mathbf{3 b}, \mathbf{4 a}$, and 6a, all observed in roughly equal yields in the product mixture.

There appears to be no sequence of (precedented) steps that would connect the emergence of the isotopomers of 5${ }^{13} \mathrm{C}_{2}$ directly with those of $\mathbf{3}, \mathbf{4}$, and $\mathbf{6}$. It is, however, plausible to invoke an alternative (and evidently minor) migratory initial rearrangement fate of $\mathbf{2}$, namely one that relies on a pathway traversed by biphenylene itself $^{1 \mathrm{~b}, \mathrm{c}}$ (Scheme 5). Among the two options open to 2 which explain the isolation of $\mathbf{5 a}$ and $\mathbf{b}$, that resulting in the former would be expected to be more favorable as it disassembles the central, more activated ring, ${ }^{13}$ thus providing a tentative rationale for the preference for $\mathbf{5 a}$. 
Scheme $5^{\mathrm{a}}$

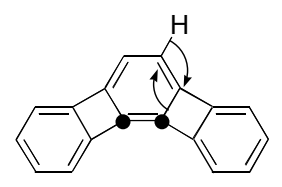

2a (214)

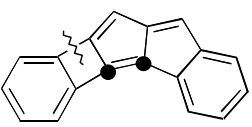

(208)
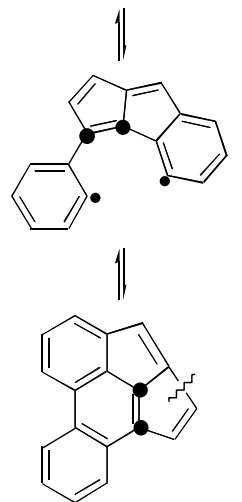

(171)

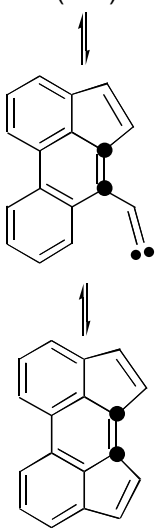

$5 a(133)$

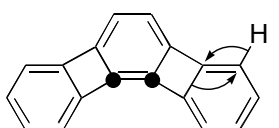

2a (214)

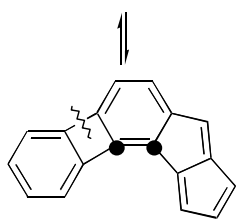

(208)

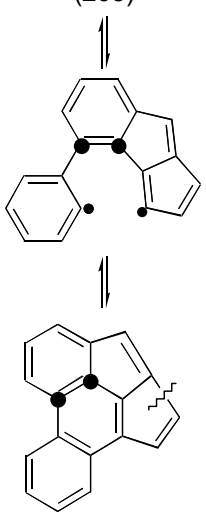

(171)

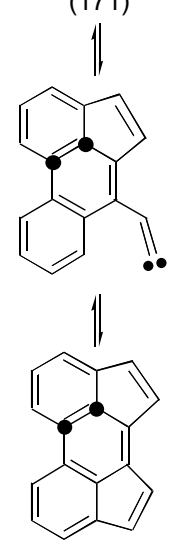

5b (133)
${ }^{a}$ Numbers in parentheses are $\mathrm{AM} 1 \Delta H_{\mathrm{f}}{ }^{\circ}$ values in $\mathrm{kcal} / \mathrm{mol}$.

In conclusion, the observed conversion of linear [3]phenylene to angular [3]phenylene demonstrates the potential of pyrolytic methods to convert phenylenes from one topology to another. This strategy might be applicable for the synthesis of new phenylenes by isomerization of known phenylenes. ${ }^{15}$ Moreover, the phenylenes represent a high-energy entry into PAHs that may aid in developing

(15) Vollhardt, K. P. C.; Mohler, D. L. In Advances in Strain in Organic Chemistry; Halton, B., Ed.; JAI: London, 1996, pp 121-160. a mechanistic understanding of PAH formation under extreme conditions. ${ }^{16}$

Acknowledgment. This work was supported by the Director, Office of Energy Research, Office of Basic Energy Sciences, Chemical Sciences Division, of the U.S. Department of Energy, under Contract DE-AC0376SF00098 and by the NSF (CHE-0071887). The Center for New Directions in Organic Synthesis is supported by Bristol-Myers Squibb as Sponsoring Member.

Supporting Information Available: Detailed experimental procedures and ${ }^{13} \mathrm{C}$ NMR spectral assignments of 3-6. This material is available free of charge via the Internet at http://pubs.acs.org.
(16) For a review, see: Wiersum, U. E., Jenneskens, L. W. In Gas Phase Reactions in Organic Symthesis;Vallée, Y., Ed.; Gordon and Breach: Amsterdam, 1997, pp 143-194. 
Scheme $3^{\text {a }}$

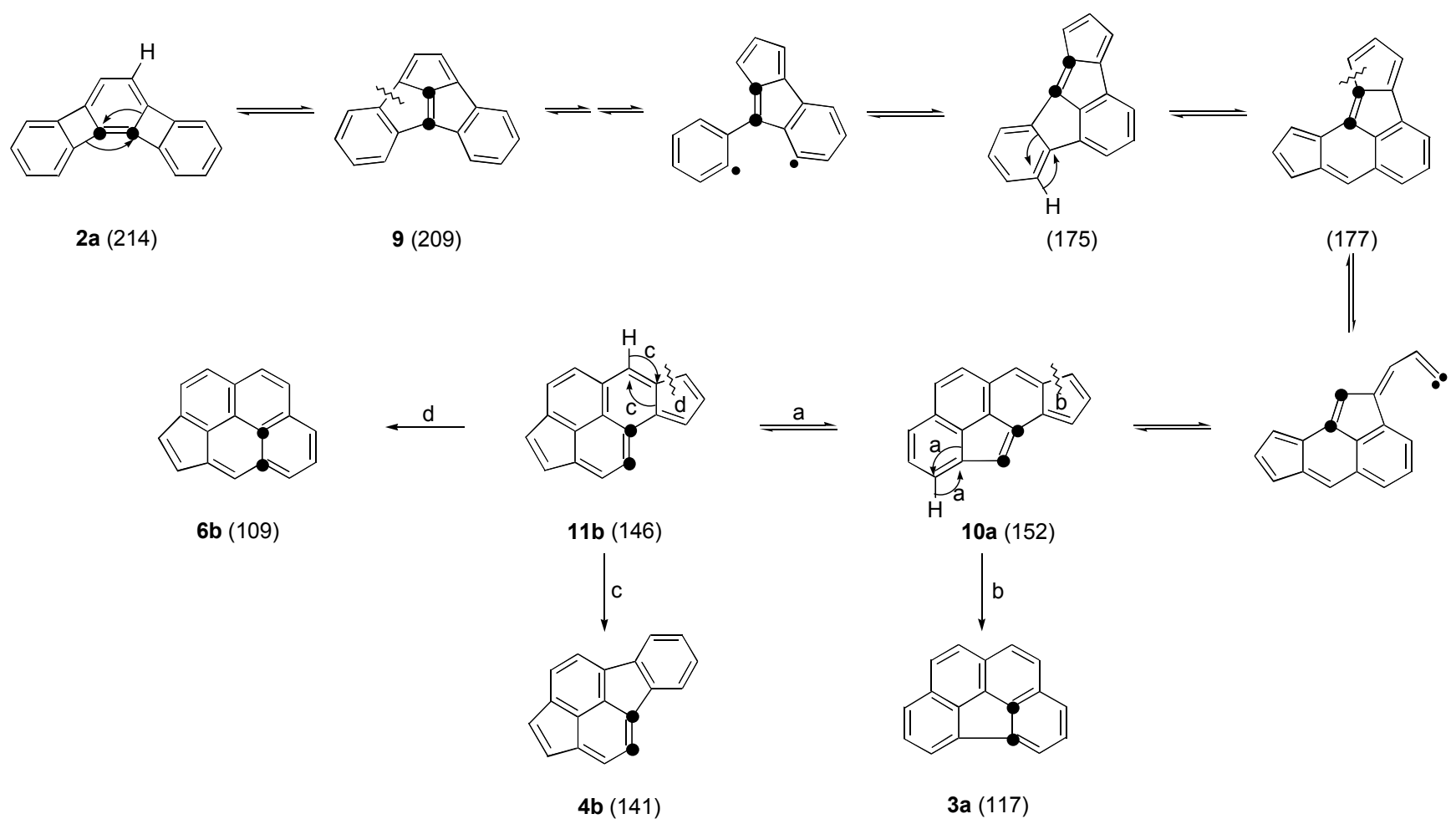

${ }^{\mathrm{a}}$ Numbers in parentheses are $\mathrm{AM} 1 \Delta H_{\mathrm{f}}{ }^{\circ}$ values in $\mathrm{kcal} / \mathrm{mol}$. 